\title{
Interhemispheric transfer and the processing of foveally presented stimuli
}

\author{
Marc Brysbaert* \\ Department of Psychology, University of Leuven, B-3000 Leuven, Belgium
}

\begin{abstract}
Two arguments are commonly given in favor of a nasotemporal overlap along the vertical meridian of the visual field: anatomical findings and the existence of macular sparing in hemianopia. A review of the literature, however, points to the weakness of the evidence. The anatomical indications are exclusively based on horseradish peroxidase studies, which can not give an unequivocal answer to the amount of overlap in central vision, and which were not supported by a recent study that made use of the more direct ["C]2deoxy-D-glucose technique. The argument of macular sparing in hemianopia appears to be derived evidence that depends on the validity of the anatomical findings. In addition, behavioral studies consistently failed to find functional confirmation of the overlap. To further test the possibility of bilateral representation in central vision, a new paradigm is proposed. It is argued that if interhemispheric transfer is needed for the processing of foveally presented stimuli, the word-beginning superiority effect should be larger for subjects with left hemisphere dominance than for subjects with right hemisphere dominance. Results are in line with the hypothesis and point to the fact that interhemispheric transfer of visual information may be involved in more processing than usually accepted. It is also noted that transfer time seems to depend on the amount of information that must be transferred, and is significantly shorter than the estimates obtained in visual half field studies.
\end{abstract}

Key words: Corpus callosum; Interhemispheric transfer; Macular sparing; Foveal vision; Optimal viewing position; Visual half field studies

\section{Interhemispheric transfer and the processing of foveally} presented stimuli

Due to the partial decussation of the optic nerves at the optic chiasm, the human visual field is split in two halves: the left and the right visual field (LVF and RVF). Both hemifields project to the contralateral cerebral hemisphere. That is, stimuli presented in the LVF are transmitted to the right cerebral hemisphere, and stimuli shown in the RVF are sent to the left cerebral hemisphere. It is not entirely clear how the visual half fields (VHFs) flank one another along the vertical meridian. Many authors seem to accept a small overlap between the two VHFs in the order of one to three degrees [40,48,51,60], but others do not [8]. Arguments in favor of a nasotemporal overlap are twofold: first, there is anatomical evidence from horseradish peroxidase studies; and, second, patients suffering from hemianopia after unilateral brain damage usually preserve

* Corresponding author. Fax: (32) (16) 286099. e-mail: fpaas02 @BLEKULILbitnet vision in the foveal region, a phenomenon called macular or foveal sparing. I will discuss the two arguments successively.

\section{Anatomical evidence of a hemiretinal overlap}

The anatomical evidence for an overlap between the nasal and the temporal hemiretina comes from studies of unilateral sectioning of the optic tract or unilateral electrophoretic injection of horseradish peroxidase (HRP) into the dorsal lateral geniculate nucleus (dLGN) [ $19,20,35,36,52,53,55]$. This technique allows tracing the ganglion cells of the retina which project to the dLGN and from there to the visual cortex. The general finding is that in a strip of about $0.2 \mathrm{~mm}$ along the vertical midline, ipsilaterally and contralaterally projecting ganglion cells intermingle. This is true both for cats and monkeys. According to Leventhal et al. $[35,36]$ the overlap is primarily due to the presence of ipsilaterally projecting cells in the nasal hemiretina, rather than to contralaterally projecting cells in the temporal hemiretina. 
Although the findings are convincing at first sight, two problems limit their usefulness for the investigation of a nasotemporal overlap in central vision: first, the horseradish procedure marks ganglion cells, which are absent in the fovea, so that the amount of overlap must be estimated; and second, if the anatomical overlap exists, its functional significance remains unclear. As for the first problem, it is well known that the ganglion cells to which the foveal receptors connect are laterally displaced, giving rise to the foveal pit. The result of this organisation for the HRP technique is that virtually no cells are stained in the foveal region and that the fovea appears as a blank spot, surrounded by a ring of stained ganglion cells. The amount of overlap in the fovea must be inferred from the number of surrounding ganglion cells marked. So, Bunt and her colleagues [ 19,20$]$ concluded from their results that the bilateral representation extended to the whole fovea (i.e. a visual area of $3 \mathrm{deg}$ ), whereas others [ 53 ] adhered a more conservative estimate of 1 deg. Wyatt [58] criticized Bunt et al.'s estimate, because the number of marked ganglion cells was too small to allow such a large overlap. According to him, data were more in line with an overlap of at most $1.5 \mathrm{deg}$ and possibly as small as 0.5 deg.

Another necessary assumption for inferring the size of foveal overlap from the number of stained ganglion cells around the foveal region is that the sweeping aside of ganglion cells away from the foveal centre occurs in an orderly manner. That is, ganglion cells on the nasal and temporal sides of the retina must have connections to foveal cones of the same side. Schein [49] discussed the anatomy of the macaque fovea and argued that there are several components of lateral displacement of retinal elements away from the centre of the mature fovea, which make it difficult for investigators to assign corresponding eccentricities in different layers of the foveal retina and to compare spatial densities of cells in the foveal representation. After discussing the different components, Schein (p. 499) concluded that "... functional crossing of the vertical meridian in the visual field may not be accurately revealed by methods tracing retrograde connection from dLGN to retinal ganglion cells."

The criticisms against the anatomical evidence for the hemiretinal overlap as revealed by the HRP technique for a long time remained theoretical and methodological. In 1988, however, Tootell et al. [56] provided the first clear empirical evidence against the overlap. They made use of the very precise [ "C]2-deoxy-D-glucose (DG) technique to study the retinotopic organization. In this technique, the eyes of a monkey are completely stabilized, the monkey is injected with DG, a stimulus is presented for several minutes, and afterwards the striate cortex is sectioned to examine which parts of the cortex have been stimulated. A duplication of the vertical meridian would imply that areas of the visual field near the vertical meridian are represented twice in striate cortex, with one representation on each hemisphere near the V 1-V2 border. Tootell et ak. found no evidence for such a duplication, although the technique had a resolution of at least $0.15 \mathrm{deg}$. This seems to further weaken the anatomical evidence of a hemiretinal overlap along the vertical meridian.

The second problem with anatomical findings is that, even if there was anatomical evidence for the existence of a nasotemporal overlap, the functional significance of such overlap should be specified. Two aspects are involved: first, is the information provided by the "wrong" cells used; and second, which functions are subserved? Colenbrander [22] was the first to suggest that, under normal circumstances, the "wrong" cells might be inhibited by the cerebral hemisphere dominant for the hemiretina in which the cells lie. Only after relaxation of the inhibition (e.g. due to injury of the cerebral hemisphere) might the information become available. A weaker hypothesis is that the "wrong" cells subserve only a limited number of functions. The most prominent function that has been proposed is that of depth perception. Bishop [5], for instance, claimed that a strict nasotemporal partition would imply that information about objects on the vertical meridian is available to each cerebral hemisphere from only one eye: closer than the fixation point only via the ipsilateral eye, and farther than the fixation point only via the contralateral eye. Thus stereopsis by binocular disparity in the region of the visual field where stereoacuity is known to be maximal, would only be possible after interhemispheric transfer. Bishop argued that such an organisation would be unlikely, and accepted the necessity of a hemiretinal overlap in the centre of the visual field. However, contrary to Bishop's position, behavioral studies [33] have indicated that acallosal patients do indeed experience severe difficulties with stereopsis on the vertical midline. This suggests that for depth perception in the centre of the visual field callosal connections are more important than any nasotempoial overlap.

\section{Foveal sparing in hemianopia}

A second argument for the existence of a nasotemporal overlap in the centre of the visual field is the finding that patients who suffer from hemianopia because of unilateral brain damage mostly preserve vision in the foveal region, a phenomenon known as foveal or macular sparing. According to several authors $[5,60]$, this phenomenon is best explained by the assumption of a bilateral representation of the fovea in the cerebral cortex. Macular sparing then is due to the fact that after unilateral brain damage the fovea is still able to send signals to the other, undamaged brain half. 
However, the argument is seriously weakened by the fact that in the ophthalmological literature two theories exist with respect to the origin of macular sparing, only one of which attributes macular sparing to a bilateral representation of the fovea. The other theory $[27,45,58]$ claims that sparing is due to (i) the enlarged representation of the central visual field at cortical levels, which increases the probability of central field survival after a random brain lesion, and (ii) the fact that the occipital cortex is supplied not only by the calcarine artery branches from the posterior cerebral artery but also by the deep optic branches of the middle cerebral artery and, in a fairly high percentage of cases, by branches from the posterior temporal artery; this helps to defend striate cortex cells representing central retina against ischemia. According to Poffenberger [46], these two theories go back to the beginning of this century with Monakow as defender of the former theory, and Munk and Henschen as proponents of the latter version.

The defenders of a bilateral representation of the fovea in the cortex base their arguments on the anatomical findings discussed in the previous section. As a matter of fact, most of the anatomical studies investigating the hemiretinal overlap were motivated by the problem of foveal sparing [ 19,35 ]. Because of that dependency, the argument of macular sparing in hemianopia, is not really additional evidence; it is indirect evidence that suffers from the same weaknesses as the anatomical findings previously discussed.

The adherents of the second theory point to a number of findings which are difficult to reconcile with the idea that foveal sparing is entirely due to bihemispheric representation. First, there is a large variability in the phenomenon. Zihl [60], for example, reported that in $30 \%$ of the cases the sparing was smaller than two degrees, whereas in $24 \%$ it was larger than 4 degrees. A second problem concerns the high incidence of patients who show no sparing at all, a phenomenon called foveal or macular splitting (not reported in Zihl [60], but about 36\% according to Celesia et al. [21 ]). This splitting of the macula is quite frequent after pregeniculate lesions, and especially after chiasmatic lesions, which does not accord with a nasotemporal overlap, unless some particular arrangement of the overlapping retinogeniculate fibres in the optic chiasma makes them more vulnerable to a lesion at this level. A third indication against the explanation in terms of a bilateral representation of the fovea is the fact that many patients with bilateral loss of vision preserve central vision as well (i.e. 27 of the 58 cases described in Symonds and MacKenzie [54]). Finally, it should be noted that behavioral studies failed to find functional consequences that may be expected from a dual representation of the visual midline (see next section and the discussion section).

\section{Findings from VHF studies}

The reasoning behind VHF studies that investigated the existence of the nasotemporal overlap is the following: if there is a hemiretinal overlap along the vertical meridian, then VHF differences found for parafoveal stimulation should not be present for stimuli displayed close to the vertical midline. Hitherto, six studies have investigated the problem and all failed to find the expected evidence.

The best controlled study probably is the one reported by Fendrich and Gazzaniga [26]. They asked a commissurotomy patient (V.P.) to compare target figures presented at various distances from the retinal midline with reference figures presented $2.5 \mathrm{deg}$ from the midline in the same or opposite field. The subject judged whether target and reference were the same. Adequate fixation of the subject was controlled with an SRI double Purkinje image eyetracker that had a resolution of $1 \mathrm{~min}$ of arc. This allowed adequate stimulus presentation as close as $0.25 \mathrm{deg}$ from fixation. It was found that targets in the same visual field as the reference were readily matched with the reference, but that accuracy dropped to chance level for targets in the opposite field. This was true for all stimulus eccentricities ranging from 0.25 to I deg from fixation. Analogous results have been reported by Harvey [28], Haun [30], Lines and Milner [38], Lines [37], and Berardi et al. [3], who all used stimulus eccentricities of at most $1 \mathrm{deg}$.

It is rather uncommon in the laterality literature to find a series of six consecutive studies that examined the same problem and reached exactly the same conclusion with different stimuli, tasks, and subjects. Therefore, the importance of these behavioral studies should not be underestimated, and they seriously question the existence of a functionally relevant overlap of the nasal and the temporal hemiretina along the vertical meridian. In this respect, they are in line with the weakness of the anatomical findings and the uncertainty about the true origin of macular sparing.

\section{Processing foveally presented words}

An attractive side-aspect of a nasotemporal overlap is that stimuli presented in the middle of the visual field are projected to both cerebral hemispheres, so that no interhemispheric transfer is needed in most normal visual processing. However, if the division between LVF and RVF is sharp, interhemispheric communication is imperative for the perception of all centrally fixated objects. During reading, for example, a fixation on the middle of a word makes the first part of the word fall in the LVF and the last part in the RVF. That is, after fixation on the center of a word, the first half of the word is initially transmitted 
to the right cerebral hemisphere, and the last half to the left cerebral hemisphere (see Fig. 1). Both parts must be combined to identify the word.

So, a way to look for the presence or absence of a nasotemporal overlap along the vertical meridian may be to examine whether one can find a time cost associated with the need for interhemispheric transfer in the processing of foveally presented words. If interhemispheric transfer is required in reading, it can be expected that subjects with language capacities mainly situated in the left hemisphere will profit to some extent from fixations on the first letter of a word, because these fixations make the whole word fall in the RVF which has direct connections to the left hemisphere. Subjects with language capacities mainly situated in the right hemisphere, on the other hand, will be at a disadvantage after fixations on the first letter of a word, because these fixations imply that the whole stimu

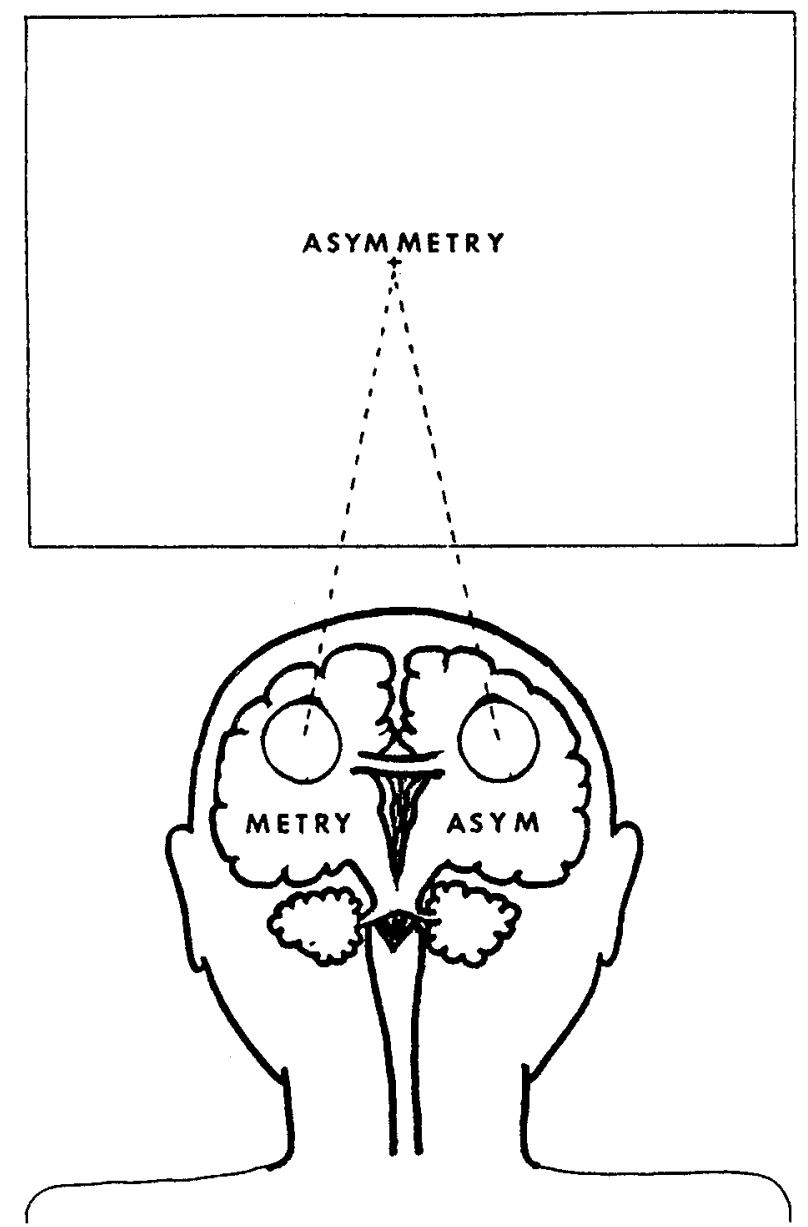

Fig. 1. In the absence of a nasotemporal overlap along the vertical midline, due to the crossing of nasal nerve fibres in the optic chiasma, stimuli left of fixation are projected to the right cerebral hemisphere and stimuli right of fixation to the left cerebral hemisphere (reprinted with permission from Brysbaert, M. and d'Ydewalle, G., Callosal transmission in reading. In G. Lifer, U. Lass and J. Shallo-Hoffmann (Eds.), Eye Movement Research: Physiological and Psychological aspects, Hogrefe, Gbttingen, 1988). lus is conveyed to the "wrong" cerebral hemisphere. The reasoning is the same as the one behind the more familiar VHF paradigm $[8,10]$. Fixations on the second, third, fourth,... letter progressively increase the amount of information that must be transferred across the commissures for subjects with left cerebral dominance, and decrease the amount of information that must be transferred for subjects with right cerebral dominance. In the end, fixations on the last letter involve transmission of the whole word in left dominant subjects, and involve no transmission any more in right dominant subjects. As interhemispheric transfer takes time, differences in transfer load should be apparent in word processing times.

The paradigm outlined above was first presented by O'Regan and colleagues $[43,44]$. They showed that word naming was shortest when subjects were allowed to fixate between the first and the middle letter of a word (see Fig. 2). This was true for word lengths ranging from 5 to 11 letters. Response latencies increased as subjects were forced to look at the extremes of the word, and more so when they were forced to look at the end than when they were forced to look at the beginning of a word. O'Regan and colleagues ascribed this pattern of results to

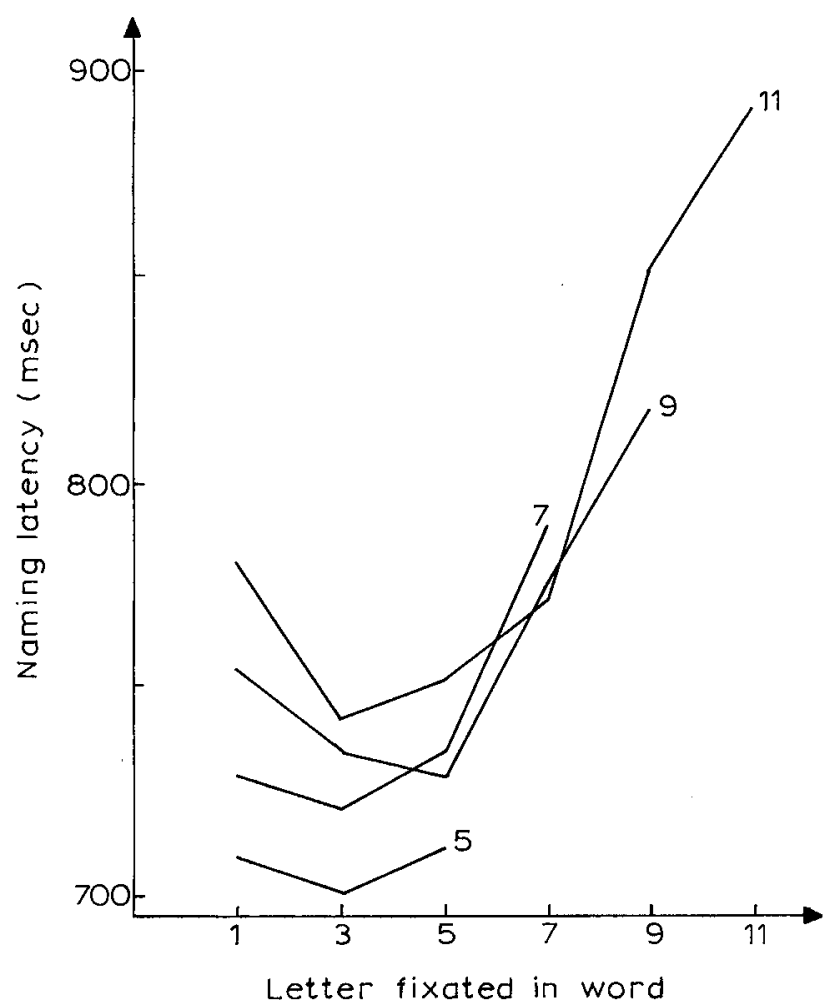

Fig. 2. Naming latency for the test word as a function of the letter position in the word that the eye was fixating at the moment the word appeared. Curves marked 5, 7, 9, 11 correspond to words of these lengths (reprinted with permission from O'Regan, J.K., Levy-Schoen, A., Pynte, J. and Brugaillere, B., Convenient fixation location within isolated worjis of different length and structure, J. Exp. Psychol.: Hum. Percept. Y

form., 10 (1984) 250-257). 
a combination of three factors. First, there is a decrease of visual acuity outside the centre of fixation. It has been shown [ $1,2,32,42]$ that the resolution of the visual system decreases rapidly for stimuli presented outside the fixation location, and certainly when these stimuli are flanked by other stimuli (i.e., the phenomenon of lateral masking or inhibition [6]). This is even true for distances less than one degree; that is, for stimuli well within the foveal area. If the decrease of visual acuity were the only significant factor, the optimal viewing position (OVP) would lie in the middle of a word and processing time would be a perfect U-shaped curve of the letter initially fixated. The faster processing of a word after fixation on the first half than after fixation on the last half, has been explained by two other factors, namely the fact that in the language studied (French) words are processed from left to right (though see Radeau et al. [47]), and the fact that most words can more easily be guessed from their first letters than from their last letters. These two linguistic factors lead to the so-called wordbeginning superiority effect.

In what follows, I will investigate whether the viordbeginning superiority effect can partly be explained by the need for interhemispheric transfer in reading. Therefore, the OVP effect will be compared for left cerebral dominant and right cerebral dominant subjects. Expectation is that if interhemispheric transfer is involved in normal word reading, the word-beginning superiority should be larger for subjects with left cerebral hemisphere dominance than for subjects with right cerebral dominance. On the other hand, the penalty of fixations towards the end of a word should be smaller for right cerebral dominant subjects than for left cerebral dominant subjects. This is because fixations on the beginning of a word make most of the word fall in the appropriate VHF for subjects with left cerebral dominance, whereas fixations on the end of word make the word fall in the appropriate VHF for subjects with right cerebral dominance. The hypothesis does not imply that the normal word-beginning superiority found for unselected subjects (90\%-95\% of whom are left cerebral hemisphere dominant [ 10]), will turn into a wordend superiority for subjects with right hemisphere dominance; it only implies that the word-beginning superiority, which is probably partly due to linguistic factors, will be smaller for subjects with right cerebral dominance.

\section{Method}

\subsection{Subjects}

Eighteen native Dutch speaking male students from the University of Leuven participated in the experiment. All were unaware of the purpose of the experiment.
Cerebral hemisphere dominance of the subjects was measured with three tachistoscopic VHF tests: a word naming, an object naming, and a clockface reading test. In the word naming test, subjects had to recognize eight series of 200 five-letter words, randomly presented in LVF and RVF. This task usually provides a clear RVF advantage in righthanded subjects [16]. The object naming test also measured processes of the dominant hemisphere (i.e. usually results in a RVF advantage for righthanded subjects [40]), and was included to make sure that the VHF asymmetries found for words, were not due to processes unrelated to cerebral asymmetry, such as reading habits. Subjects had to name line drawings of five familiar objects (apple, house, clock, lamp, and cupboard) as fast as possible. Each subject finished four series of 488 stimuli, randomly presented in LVF and RVF. The last task, clockface reading, was included to assess processing of the non-dominant task. Subjects had to estimate what time was indicated on a circular clock without numerical time marks. The test usually results in a LVF advantage for righthanded persons $[4,29,39]$. Each subject finished two series of 288 stimuli. The clock face reading test was included to assert that the VHF asymmetries of the first two tasks were not due to attentional biases of the subjects in favor of one or the other VHF, and/or to differences in the speed between the afferent pathways of the two hemifields [31,34].

VHF asymmetries were measured with two indices: The point-biserial correlation index for latency data, and the lambda index for accuracy data. The point-biserial correlation index is calculated with the following equation: $r p b=((R \mathrm{TL}-\mathrm{R} T R) / S) \mathrm{x}$ $(P Q) 112$, in which $R$ TL and $R T R$ stand for the mean reaction latencies in LVF and RVF, $\mathrm{P}$ and $Q$ for the proportions of stimuli presented to LVF and RVF, and $\mathrm{s}$ for the standard deviation of all reaction latencies. The point-biserial correlation ranges from -1 to +1 ; a positive index indicates a RVF superiority, a negative index a LVF superiority. The lambda index is obtained with the equation: $L=\ln \left(\mathrm{R}+/ \mathrm{R}_{-}\right)-\ln \left(\mathrm{L}_{+} / \mathrm{L}_{-}\right)$, in which $\mathrm{R}+$ and $L+$ represent the number of correct responses in RVF and LVF, and $\mathrm{R}_{-}$and $L$ the numbers of incorrect responses in RVF and LVF. A positive lambda, which can vary from - oo to + oc, just like a positive point-biserial correlation index, indicates a RVF superiority, a negative lambda index represents a LVF superiority. Lambda indices were not calculated for the object naming test and the clockface reading test, because they are assumed not to reveal valuable information in the latter case [4,39], and error rate was less than $2 \%$ in the former case. The point-biserial correlation index and the lambda index of laterality were preferred to other indices, because they allow detailed analysis of individual data $[16,17]$. Per subject 1,600 observations were made on the 
word naming test, 1,152 on the object naming test, and 576 on the clockface reading test. This ensured rather reliable test results with small confidence intervals.

Out of a total sample of 19 righthanders and 68 lefthanders, two groups of subjects were drawn: one group of nine subjects with laterality indices that were in agreement with left cerebral hemisphere dominance, and another group of nine subjects with laterality indices that either pointed to right hemisphere dominance or at least to very reduced left hemisphere dominance. Mean rpb on the word naming test was.315 for the left dominant subjects (range: 0.221 to 0.454 ), and 0.016 for the other subjects (range: -0.117 to 0.109 ); mean Ls on the word naming test were 1.54 (range: 0.81 to 2.00 ) and 0.50 (range: -0.08 to 1.08 ) respectively. The average rpb on the object naming latency test was 0.078 (range: 0.021 to 0.125 ) for the left dominant subjects, and -0.012 (range: -0.093 to 0.041 ) for the others. Finally, mean rpb on the clockface reading test was -0.058 (range: -0.147 to 0.011 ), and 0.016 (range: -0.100 to 0.149 ) respectively. The overlap of the different indices between both groups was due to the fact that the VHF asymmetries on the three laterality tasks not always formed an unequivocal pattern of results. Nevertheless, the differences between the groups are reliable for each index.

Eight of the nine subjects with left hemisphere dominance were righthanded; this was also the case for two subjects with reversed hemisphere dominance. The others were lefthanded. All subjects had normal or corrected-tonormal vision, and had recognized at least $40 \%$ of the words in the tachistoscopic VHF word naming test of laterality. Two of the subjects with right hemisphere dominance had participated in a preliminary experiment [15].

\subsection{Stimuli}

The stimulus sample consisted of 482 words, 90 of which were three-letter words, 96 four-letter words, 100 fiveletter words, 96 seven-letter words, and 100 nine-letter words. The three and four-letter words were subdivided in three classes: high-frequency words (mean frequency three-letter words $=3677 / 720,000$; range: 235-18362; mean frequency four-letter words $=1366 / 720,000$; range 289-6654 [57]), low-frequency words that differed from the high-frequency words by the first letter (mean frequency three-letter words $=9 / 720,000$; range: $0-44$; mean frequency four-letter words $=15 / 720,000$; range $0-143$ ), and low-frequency words that differed from the high7frequency words by the last letter (mean frequency three-letter words $=13 / 720,000$; range: $0-71$; mean frequency fourletter words $=11 / 720,000$; range: $0-67$ ). The effects of this manipulation on the optimal viewing effect will be discussed elsewhere. The five, the seven, and the nine-letter words consisted of a high-frequency half and a rather low-frequency half (five-letter words: high-frequency = $301 / 720,000$, range 92-2335; low-frequency $=60 / 720,000$, range 40-87; seven-letter words: high-frequency $=138 / 720,000$, range 69-411; low-frequency $=55 / 720,000$, range 41-69; nine-letter words: high-frequency $=102 / 720,000$, range 50-336; low-frequency $=39 / 720,000$, range $18-91$ ). Words of five letters or longer with a very low frequency were not chosen, because I wanted the words to be identifiable at tachistoscopic presentation of $160 \mathrm{~ms}$. Nouns, verbs, adjectives, and function words were mixed to get a sample of the total language corpus [57].

Words were presented in lower case and had a length of $3 \mathrm{~mm}$ per letter. Subjects were sitting at a normal reading distance between 40 and $60 \mathrm{~cm}$ (there were no head restraints). At a distance of $57 \mathrm{~cm}$, stimulus magnitude of $10 \mathrm{~mm}$ coincides with a visual angle of $1 \mathrm{deg}$.

\subsection{Procedure}

Subjects were sitting in front of a CRT display. They were told to fixate a gap between two vertically aligned lines in the middle of the screen. In order to ensure adequate fixation, at a random time interval [ 13 ], a digit between 0 and 9 was presented between the fixation lines for $40 \mathrm{~ms}$ followed by a mask ( ), instead of a word. Subjects had to identify the digit and were warned by a tone if they made a mistake. The experimenter told them that more than $10 \%$ of the fixation stimuli missed made the series invalid. Although this only occasionally happened, it made the subjects very alert to look at the fixation location on every trial.

Stimuli were presented with an IBM XT microcomputer connected to a Philips 12" monochrome monitor. The computer collected the responses by means of a voice trigger, with both stimulus and response timing performed to the nearest ms using software routines published by Brysbaert and colleagues [7,12,14]. Words were presented for $160 \mathrm{~ms}$ and then masked to circumvent screen persistency. The mask consisted of ASCII codes 178 (\$) and had the same length as the stimulus word. The mask remained on the screen until the subject reacted. As soon as the subject named the word, the experimenter checked the correctness of the response and the adequacy of the time measurement. The latter could be noticed by looking if the mask disappeared too quickly or too late with respect to the subject's answer. Incorrect responses or bad reaction times led to a second presentation of the stimulus at a random place later in the series. A mistake on the second occasion was considered as a failure. A new trial started automatically 700 $\mathrm{ms}$ after the experimenter typed in his response. The fixation mark remained visible throughout the whole experiment.

Words were presented in such away that subjects fixated 
a different letter position. For the three-, the four-, and the five-letter words, this could be every possible letter position; for the seven- and the nine-letter words, only the odd letter position were fixated. The place where the subject fixated varied randomly from trial to trial. The position in a particular word on which the subject had to fixate was varied over sessions according to a latin-square design. As every subject finished 15 sessions, the latin-square was repeated five times for the three-letter words (three different fixation positions), almost four times for the four- and the seven-letter words (four fixation positions), and three times for the fiveand the nine-letter words (five fixation positions). A session of 482 words (plus some missed trials) and about 96 digits lasted more or less $20 \mathrm{~min}$. The experiment was run in three periods of $2 \mathrm{~h}$. To motivate the subjects, after each series feedback was given about the number of incorrect trials, the mean reaction time, and the number of fixation stimuli missed. A series could be interrupted any time, in order to give the subjects a rest. Every subject finished around $482 \times 15=7,230$ word trials.

\section{Results}

Mean percentage of fixation digits missed amounted to $2 \%$. This ensures that subjects were indeed looking at the fixation location when the stimuli appeared. In general, subjects were rather eager to try not to miss a single digit. Percentage of stimuli that had to be presented twice before they were correctly named, amounted to $1.2 \%$. There was a slight increase as the words grew longer (e.g. three-letter words: $0.9 \%$, nine-letter words: $1.5 \%$ ), and when the sub jects were looking at letters on the extremes, certainly on the end (e.g. for the nine-letter words, percentages amounted to $1.5 \%$, $0.9 \%, 0.9 \%, 1.2 \%$, and $2.8 \%$ for fixations on the first, the third, the fifth, the seventh, and the ninth letter respectively). Percentage of stimuli that after two trials did not yield a valid time estimate or a correct recognition amounted to $0.4 \%$. There were no differences between word lengths, but the percentage was slightly higher for fixations on the last letter of the sevenletter words and the nine-letter words (i.e. $0.5 \%$ for the seven-letter words, and $0.7 \%$ for the nine-letter words).

Fig. 3 displays the naming latencies as a function of word length, letter fixated, and cerebral dominance of the subjects. As can be seen, the hypothesized smaller wordbeginning superiority effect for subjects with right cerebral hemisphere dominance was present. Statistical analysis of the data confirmed the impression.

An overall analysis of variance on the raw data was not possible because the number of levels of the variable "Letter fixated" differed between word lengths and the intervals between the levels were not the same (i.e. every letter of the short words was fixated, whereas for the long words this was only true for the odd letters). Therefore, separate analyses were computed for the different word lengths. A priori expectation was that we would find an interaction between the variables "Letter fixated" and "Cerebral dominance", preferentially in the absence of a main effect of Cerebral dominance. This is indeed what we obtained: the F-values associated with the main effect of Cerebral dominance were smaller than 1 for each word length, whereas the F-values associated with the interaction were significant on the.01 level for all word lengths except for the four-letter words [three-letter words:

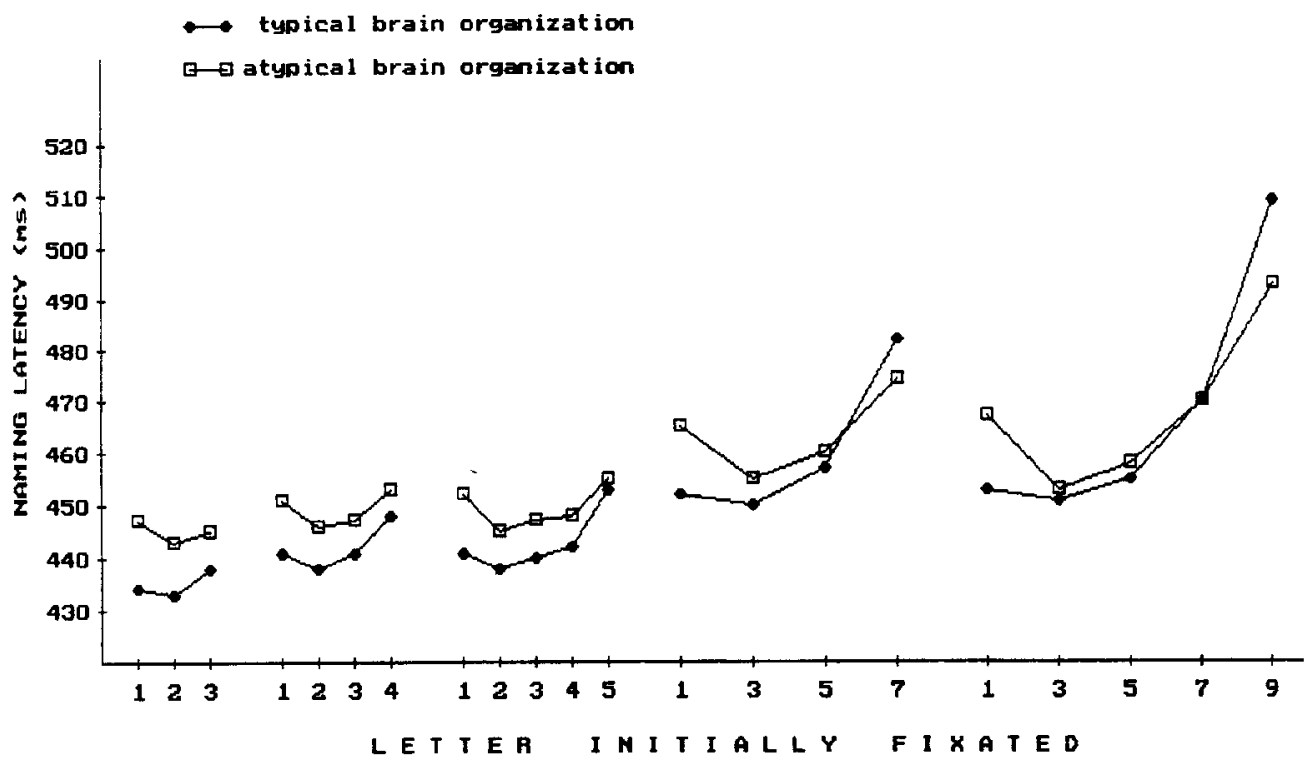

Fig. 3. Word naming latency as a function of cerebral dominance, word length, and letter fixated. 
Table 1 Estimates of interhemispheric transfer time per letter (in ms) based on the comparison of successive fixation positions for the different word lengths

Fixation positions

\begin{tabular}{lrrrr} 
& $1-2$ & $2-3$ & $3-4$ & $4-5$ \\
\hline 3-letter words & 1.5 & 1.5 & & \\
4-letter words & 1.0 & 1.0 & 0.5 & \\
5-letter words & 2.0 & 2.0 & 0.5 & 2.0 \\
7-letter words & 2.0 & 0.5 & 2.8 & \\
9-letter words & 3.0 & -0.2 & 0.8 & 4.0 \\
\hline
\end{tabular}

$F 2,32=5.82, \mathrm{MSe}=7.28$; four-letter words: $F 3,48=1.88, \mathrm{MSe}=$ 11.36; five-letter words: $F 4,64=5.38, \mathrm{MSe}=9.53$; seven-letter words: $F 3,48=6.50, \mathrm{MSe}=47.69$; nine-letter words: $F 4,64=6.24$, $\mathrm{MSe}=81.16]$. In addition, the main effect of Letter fixated was significant for all word lengths [three-letter words: $F 2,32=9.17$, $\mathrm{MSe}=7.28$; four-letter words: $F 3,48=21.26$, MSe $=11.36$; five-letter words: $F 4.64=44.81, \mathrm{M} \mathrm{Se}=9.53$; seven-letter words: $F 3,48=46.91, \mathrm{MSe}=47.69$; nine-letter words: $F 4,64=84.73, \mathrm{MSe}=$ 81.16].'

Planned comparisons showed that the interaction between Letter fixated and Cerebral dominance was mainly due to differences in linear trend between the two groups of subjects. The differences in the linear trend explained $96 \%$ of the sum of squares of the interaction for the threeletter words, $99 \%$ of the sum of squares of the (nonsignificant) interaction for the four-letter words, $86 \%$ for the five-letter words, $93 \%$ for the seven-letter words, and $84 \%$ for the nine-letter words.

Because the interaction between Letter fixated and Cerebral dominance was mainly due to a discrepancy in linear trend, the difference between the two groups of subjects was a function of the number of letters that needed to be transferred from one hemisphere to the other. This can be shown by applying the following equation to the data:

$$
\mathrm{IHTT}=\frac{\left[\left(R T_{\mathrm{j}}(\mathrm{LD})-R T_{\mathrm{i}}(\mathrm{LD})\right)-\left(R T_{\mathrm{j}}(\mathrm{RD})-R T_{\mathrm{i}}(\mathrm{RD})\right)\right]}{\left[\left(N_{\mathrm{j}}(\mathrm{LD})-N_{\mathrm{i}}(\mathrm{LD})\right)-\left(N_{\mathrm{j}}(\mathrm{RD})-N_{\mathrm{i}}(\mathrm{RD})\right)\right],}
$$

in which IHTT $=$ interhemispheric transfer time, $R$ Ti(LD) and $R$ $\mathrm{T} ;(\mathrm{RD})=$ naming latency after initial fixation on the ith letter position for the left (LD) and right dominant (RD) subjects, $\mathrm{Ni}(\mathrm{LD})$ and $\mathrm{Ni}(\mathrm{RD})=$ number of letters that need to be transferred for the left and right dominant subjects according to the model outlined in Fig. 1. Table 1 shows the estimates obtained for the different word lengths by comparing the successive fixation positions. It can be seen that all estimates are roughly equal and vary around $1.6 \mathrm{~ms}$.

\section{Discussion}

Starting from the finding that there was little evidence of a hemiretinal overlap along the vertical meridian of the visual field, I hypothesized that the VHF asymmetries found for parafoveally presented stimuli, would also exist for foveally presented stimuli. More specifically, I expected that the RVF superiority for words normally obtained for righthanded subjects, would lead to a larger wordbeginning superiority for subjects with left cerebral hemisphere dominance than for subjects with right cerebral hemisphere dominance. To test the hypothesis, the OVP pattern for both subject samples was measured.

A test battery was developed to assess cerebral dominance of normal subjects. This battery consisted of three tachistoscopic VHF tasks: word naming, object naming, and clockface reading. The first task was chosen because of its large similarity with the OVP task. The second task was added to validate the results of the first, and to make sure that the VHF asymmetry revealed by the first test was not due only to reading habits. The third task, finally, was expected to yield a VHF asymmetry opposite to the first tests, and was included to ensure that the VHF asymmetries were not due to attentional biases and/or differences in speed between the afferent pathways. Although the test battery did not produce unequivocal cerebral dominance patterns for all subjects, it was possible to discriminate two groups of subjects that differed from each other in the predicted way.

The predictions with respect to the OVP effect were confirmed (see Fig. 3): subjects with left cerebral hemisphere dominance profited more from fixations on the beginning of a word than subjects with right cerebral hemisphere dominance, whereas the reverse was true for fixations on the end of a word. Thus, left cerebral dominant subjects had a significantly larger word-beginning superiority effect than right cerebral dominant subjects. This was already true for three-letter words which subtended a visual angle of less than one degree.

An objection against the interpretation of the results in terms of interhemispheric transfer, might be that cerebral dominance was assessed with VHF tasks. There is indeed some controversy in the literature to what extent VHF asymmetries are an indication of hemispheric specialization, and not caused by other factors such as attention 
allocation, reading habits, and the like [ $11,24,31,34]$. So, it might be argued that the findings with foveal and parafoveal vision correlated for reasons unrelated to cerebral dominance and interhemispheric transfer. As long as there are no other means than behavioral techniques to assess hemispheric specialization in normal subjects, this criticism will remain. However, it should be noted that the criticism is to some extent controlled for by the precaution I took to include different tasks with opposite VHF asymmetries in the battery of laterality tests. This precludes any explanation in terms of a systematic attentional bias or a general VHF superiority. After all, the subjects with RVF advantages for the word naming and the object naming task, showed a clear LVF advantage on the clockface reading task and vice versa.

If the difference between the two groups of students is due to the need for interhemispheric transfer after foveal presentation, the data indicate that acallosal subjects will have difficulties in recognizing tachistoscopically presented words in the center of the visual field. Two studies have been reported which investigated this question. Sergent [50] presented four-letter stimuli which subtended a visual angle of $4 \mathrm{deg}$, and asked two commissurotomy patients (L.B. and N.G.) to indicate whether the stimuli were words or non-words. She found that performance on trials with central presentation was lower than on trials with unilateral presentation, though still being significantly above chance (L.B.: 75\% correct; N.G.: $70 \%$ correct). Recently, Corballis and Trudel [23] criticized Sergent's study, because she used too few stimuli which in addition had been presented several times on unilateral trials before, so that guessing on the basis of partial information was possible. On an improved version of the task, Corballis and Trudel reported that L.B. was at chance level (56\% correct) with central presentation and clearly worse than unilateral LVF ( $82 \%$ correct) or RVF trials (99\% correct). Similar results were reported for a second patient, D.K., who had $57 \%$ correct responses on foveal trials, $73 \%$ correct responses on LVF trials, and $96 \%$ correct responses on RVF trials. These findings are very well in line with the conclusions drawn from the present study.

Two more aspects of the data should be mentioned. First, the difference between the groups of subjects was rather small; and second, the effect seemed to depend on the number of letters that had to be transferred. As for the first aspect, the difference between the left cerebral dominant subjects and the right cerebral dominant subjects after fixations on the first and on the last letter amounted to $6 \mathrm{~ms}$ for the three-letter words, $5 \mathrm{~ms}$ for the four-letter words, $9 \mathrm{~ms}$ for the seven-letter words, $21 \mathrm{~ms}$ for the seven-letter words, and $30 \mathrm{~ms}$ for the nine-letter words. This is to be opposed to the differences usually found in
VHF tasks. For instance, the difference between both groups on the VHF word naming task, in which five-letter words were used, amounted to $76 \mathrm{~ms}$ (i.e., a RVF superiority of $90 \mathrm{~ms}$ for the left cerebral dominant subjects, versus a RVF advantage of $14 \mathrm{~ms}$ for the right cerebral dominant subjects); that is, a difference of eight times the one found for the foveally presented stimuli. Similarly, the difference amounted to $17 \mathrm{~ms}$ for the object naming test, and to $35 \mathrm{~ms}$ for the clockface reading test (i.e., well above the difference for the foveally presented short words). Other VHF tasks also reveal VHF asymmetries of $15 \mathrm{~ms}$ and more [8]. One paradigm in the laterality literature, however, returned estimates of interhemispheric transfer time very similar to ours. In visual masking studies (for a review, see Moscovitch [41]), it has repeatedly been observed that the critical interstimulus interval between a target three-letter word and a pattern mask is three to five milliseconds shorter for stimuli presented in the RVF than for stimuli presented in the LVF. Moscovitch [41] considered this value as an unbiased estimate of interhemispheric transmission time.

A second remarkable aspect of the data was that the difference between the two groups of subjects seemed to depend on the number of letters that had to be transferred from one hemisphere to the other. Because of this, the interaction between "cerebral dominance" and "letter fixated" was mainly due to a difference in linear trend between both groups of subjects (see Results). The difference amounted to $1.6 \mathrm{~ms}$ per letter and was insensitive to word length. Only for long words was there some evidence that the cost related to the transmission of letters at the extremes was larger than the cost associated with letters in the middle (see Table 1). Although unexpected, this finding is not without an analog in the laterality literature. There too, it has been shown that the RVF superiority for words increases with increasing word length. This is true for accuracy [9,59] and for latency [16,18,25]. Ellis et al. [25] suggested that the increase in VHF asymmetry for longer words is due to the fact that abstract letter identities are transmitted over the corpus callosum. A similar explanation might be invoked for the present findings, which would imply that interhemispheric transfer for verbal stimuli is a serial, letter by letter, process. Alternative interpretations are (i) that the constant transfer cost per letter is only true for averaged data while on the word level information chuncks larger than a letter are transmitted (with a greater time cost), or (ii) that interhemispheric transfer time, due to stimulus degradation, depends on the distance between the letters and the center of the visual field, as proposed by Bryden and Bulman-Fleming (this issue).

Together with the findings mentioned in the introduction and the discussion, the present data provide convinc 
ing evidence that interhemispheric transfer is an essential element in foveal perception. There are no indications that the centre of the visual field is bilaterally represented. Rather, the data suggest that the time cost associated with distributed input is small enough to overcome the "inconvenience" of having the information initially divided over the two brain halves.

References

[1] Alpern, M., Muscular mechanisms. In H. Dawson (Ed.), The Eye Vol. 3, Academic Press, New York, 1962

[2] Anstis, S.M., A chart demonstrating variations in acuity with reti nal position, Vis. Res., 14 (1974) 589-592.

[3] Berardi, N., Fiorentini, A. and Gravina, A., Functional dissociation of the hemispheres in the discrimination of complex gratings near the vertical meridian, Vis. Res., 28 (1988) 491-496.

[4] Berlucchi, G., Brizzolara, D., Marzi, C.A., Rizzolatti, G. and Umilta, C., The role of stimulus discriminability and verbal codability in hemisphere specialization for visuospatial stimuli, Neuropsychologia, 17 (1979) 195-202.

[5] Bishop, P.O., Binocular vision. In R.A. Moses and W.M. Hart Jr. (Eds.), Adler's Physiology of the Eye, Mosby, St. Louis, 1987, pp. 619-689.

[6] Bouma, H., Interaction effects in parafoveal letter recognition, $\mathrm{Na}$ ture, 226 (1970) 271-272.

[7] Bovens, N. and Brysbaert, M., IBM PC/XT/AT and PS/2 Turbo Pascal timing with extended resolution, Behav. Res. Meth. Instr. Comp., 22 (1990) 332-334.

[8] Bradshaw, LL, Hemispheric Specialization and Psychological Func tion, Wiley, Chichester, 1989.

[9] Bruyer, R. and Janlin, D., Lateral differences in lexical access: word length vs stimulus length, Brain Lang., 37 (1989) 258-265.

[10] Bryden, M.P, Laterality: Functional Asymmetry in the Intact Brain, Academic Press, New York, 1982.

[ 11 ] Bryden, M.P. and Mondor, T.A., Attentional factors in visual field asymmetries, Can. J. Psychol., 45 (1991) 427-447.

[12] Brysbaert, M., A warning about millisecond timing in Turbo Pas cal, Behav. Res. Meth. Instr. Comp., 22 (1990) 344-345.

[13] Brysbaert, M., Algorithms for randomness in the behavioral sci ences: a tutorial, Behar. Res. Meth. Instr. Comp., 23 (1991) 45-60.

[ 14] Brysbaert, M., Bovens, N., d'Ydewalle, G. and Van Calster, J., Turbo Pascal timing routines for the IBM microcomputer family, Behav. Res. Meth. Instr. Comp., 21 (1989) 73-83.

[15] Brysbaert, M. and d'Ydewalle, G., Callosal transmission in reading. In G. Luer, U. Lass and J. Shallo-Hoffmann (Eds.), Eye Movement Research: Physiological and Psychological Aspects, Hogrefe, Gottingen, 1988, pp. 246-266.

[ 16] Brysbaert, M. and d'Ydewalle, G., Tachistoscopic presentation of verbal stimuli for assessing cerebral dominance: Reliability data and some practical recommendations, Neuropsychologia, 28 (1990) 443-455.

[ 17] Brysbaert, M. and d'Ydewalle, G., Individual analysis of laterality data, Neuropsychologia, 28 (1990) 901-916.

[ 18$]$ Bub, D. N. and Lewine, J., Different modes of word recognition in the left and right visual fields, Brain Lang., 33 (1988) 161-188.

[19] Bunt, A.H. and Minckler, D.S., Foveal sparing: new anatomical evidence for bilateral representation of the central retina, Arch. Ophthalmol., 95 (1977) 1445-1447.

[20] Bunt, A.H., Minckler, D.S. and Johanson, G.W., Demonstration of bilateral projection of the central retina of the monkey with horseradish peroxidase neuronography, J. Comp. Neurol., 171 (1977) 619-630.

[21] Celesia, G.G., Meredith, J.T. and Pluff, K., Perimetry, visual evoked potentials and visual evoked spectrum array in homonymous hemianopsia, Electroencephalogr. Clin. Neurophysiol., 56 (1983) 16-30.

[22] Colenbrander, M.C., Sparing of the macula, Ophthalmology, 171 (1975) 91-94

[23] Corballis, M.C. and Trudel, C.I., The role of the forebrain com missures in interhemispheric integration. Neuropsychology, in press.

[24] Efron, R., The Decline and Fall of Hemispheric Specialization, Er lbaum, Hillsdale, NJ, 1990.

[25] Ellis, A.W., Young, A.W. and Anderson, C., Modes of word recognition in the left and right cerebral hemispheres, Brain Lang., 35 (1988)254-273.

[26] Fendrich, R. and Gazzaniga, M.S., Evidence of foveal splitting in a commissurotomy patient, Neuropsychologia, 27 (1989) 273-281.

[27] Harrington, D.O., The Visual Fields, Mosby, St. Louis, 1981.

[28] Harvey Jr., L.O., Single representation of the visual midline in humans, Neuropsychologia, 16 (1978) 601-610.

[29] Hatta, T., Visual field differences in a mental transformation task, Neuropsychologia, 16 (1978) 725-733.

[30] Haun, F., Functional dissociation of the hemispheres using foveal visual input, Neuropsychologia, 16 (1978) 725-733.

[31 ] Hellige, J.B., Bloch, M.I. and Taylor, A.K., Multitask investigation of individual differences in hemispheric asymmetry, J. Exp. P.sychol.: Hum. Percept. Perform., 14 (1988) 176-187.

[32] Jacobs, R.J., Visual resolution and contour interaction in the fovea and periphery, Vis. Res., 19 (1979) 1187-1196.

[33] Jeeves, M.A., Stereo perception in callosal agenesis and partial collosotomy, Neuropsychologia, 29 (1991) 19-34.

[34] Kim, H. and Levine, S.C., Sources of between-subjects variability in perceptual asymmetries: a meta-analytic review, Neuropsychologia, 29 (1991) 877-888.

[35] Leventhal, A.G., Ault, S.J. and Vitek, D.J., The nasotemporal division in primate retina: the neural bases of macular sparing and splitting, Science, 240 (1988) 66-67.

[36] Leventhal, A.G., Ault, S.J., Vitek, D.J. and Shou, T., Extrinsic determinants of retinal ganglion cell development in primates, J. Comp. Neurol., 286 (1989) 170-189.

[37] Lines, C.R., Nasotemporal overlap investigated in a case of agen esis of the corpus callosum, Neuropsychologia, 22 (1984) 85-90.

[38] Lines, C.R. and Milner, A.D., Nasotemporal overlap in the human retina investigated by means of simple reaction time to lateralized light flash, Exp. Brain Res., 50 (1983) 166-172.

[39] Marino, M.F. and McKeever, W.F., Spatial processing laterality and spatial visualization ability: relations to sex and familial sinistrality variables, Bull. Psychon. Soc., 27 (1989) 135-137.

[40] McKeever, W.F., Tachistoscopic methods in neuropsychology. In ILL Hannay (Ed.), Experimental Techniques in Human Neuropsychology, Oxford University Press, New York, 1986, pp. 167-211.

[41] Moscovitch, M., Hemispheric specialization, interhemispheric codes, and transmission times: inferences from visual masking studies in normal people. In F. Lepore, M. Ptito and H.H. Jasper (Eds.), Two Hemispheres-One Brain, Alan Liss, New York, 1986, pp. 483-510.

[42] Nazir, T.A., Heller, D. and Sussmann, C., Letter visibility and word recognition: the optimal viewing position in printed words, Percept. Psychophys., 52 (1992) 315-328.

[43] O'Regan, J.K., The convenient viewing position hypothesis. In D.F. Fisher, R.A. Monty, and J.W. Senders (Eds.), Eye Movements: Cognition and Visual Perception, Erlbaum, Hillsdale, NJ, 1981, pp. 289-298.

[44] O'Regan, J.K., Levy-Schoen, A., Pyrite, J. and Brugaill\&e, B., Convenient fixation location within isolated words of different length and structure, J. Exp. Psychol.: Hum. Percept. Perform., 10 (1984) 250-257.

[45] Perenin, M.T. and Vadot, E., Macular sparing investigated by means of Haidinger brushes, Br. J. Ophthalmol., 65 (1981) 429435.

[46] Poffenberger, A.T., Reaction time to retinal stimulation, with spe- 
cial reference to the time lost in conduction through nerve centers,

Arch. Psychol., 23 (1912) 1-73.

[47] Radeau, M., Morais, J., Mousty, Ph., Saerens, M. and Bertelson, P., A listener's investigation of printed word processing, J. Exp. Psychol.: Hum. Percept. Perform., 18 (1992) 861-871.

[48] Rayner, K. and Pollatsek, A., The Psychology of Reading, Prentice Hall, Englewood Cliffs, NJ, 1989.

[49] Schein, S.J., Anatomy of macaque fovea and spatial densities of neurons in foveal representation, J. Comp. Neurol., 269 (1988) 479505

[50] Sergent, J., A new look at the human split brain, Brain, 110 (1987) 1375-1392.

[51] Sergent, J., Les dilemmes de la gauche et de la droite: opposition, cohabitation ou cooperation? In X. Seron (Ed.), Psychologie et Cerveau, Presses Universitaires de France, Paris, 1989, pp. 121151.

[52] Stone, J., The nasotemporal division of the cat's retina, J. Comp. Neurol., 126 (1966) 585-600.

[53] Stone, J., Leicester, L. and Sherman, S.M., The naso-temporal division of the monkey's retina, J. Comp. Neurol., 150 (1973) 333348.
[54] Symonds, C. and MacKenzie, L, Bilateral loss of vision from ce rebral infarction, Brain, 80 (1957) 415-455.

[55] Terao, N., Inatomi, A. and Maeda, T., Anatomical evidence for the overlapped distribution of ipsilaterally and contralaterally projecting ganglion cells to the lateral geniculate nucleus in the cat retina: a morphologic study with fluorescent tracers, Invest. Ophthalmol. Vis. Sci., 23 (1982) 796-798.

[561 Tootell, R.B.H., Switkes, E., Silverman, M.S. and Hamilton, S.L., Functional anatomy of macaque striate cortex: II. Retinotopic organization, J. Neurosci., 8 (1988) 1531-1568.

[57] Uit den Bogaart, P.C, Woordfrequenties in Geschreven en Gesproken Nederlands, Oosthoek, Scheltema \& Holkema, Utrecht, 1975.

[58] Wyatt, H.J., Nasotemporal overlap and visual field sparing, Invest. Ophthalmol. Vis. Sci., 17 (1978) 1128-1130.

[59] Young, A.W. and Ellis, Aw., Different methods of lexical access for words presented in the left and right visual hemifield, Brain Lang., 24 (1985) 326-358.

[60] Zihl, J., Cerebral disturbances of elementary visual functions. In J.W. Brown (Ed.), Neuropsyehology of Visual Perception, Erlbaum, Hillsdale, NJ, 1989, pp. 35-58. 